International Journal of Legal Medicine, Volume 135, January 2021, pp. 359-364

DOI: $10.1007 / \mathrm{s} 00414-020-02377-y$

\title{
Dental age estimation based on pulp chamber/crown volume ratio measured on CBCT images in a Spanish population
}

\section{Ana Molina • Manuel Bravo • Gabriel M. Fonseca • Nicholas Márquez-Grant • Stella Martín-de-las-Heras}

S. Martín-de-las-Heras $(\bowtie) \cdot A$. Molina

Department of Forensic Medicine, University of Malaga, 29071 Malaga, Spain. e-mail: smdelasheras@uma.es

M. Bravo, Department of Preventive and Community Dentistry, University of Granada, 18071 Granada, Spain.

G.M. Fonseca, Centro de Investigación en Odontología Legal y Forense (CIO), Facultad de Odontología, Universidad de la Frontera, Temuco, Chile

N. Márquez-Grant, Cranfield Forensic Institute, Cranfield University, Defence Academy of the United Kingdom, Shrivenham SN6 8LA, United Kingdom.

\section{Highlights}

Chronological age was related to pulp chamber/crown volume ratio in a Spanish population Upper incisor ratios revealed the strongest correlation

The pulp chamber/crown volume ratio explained $36.6 \%$ of the age variability

The difference between chronological and dental age was $<5$ years in $31.3 \%$ of the sample This method of dental age estimation is gender-independent

ORCID: Stella Martin-de-las-Heras https://orcid.org/0000-0002-1554-951X

Manuel Bravo https://orcid.org/0000-0001-5508-561X

Nicholas Márquez-Grant https://orcid.org/0000-0002-5812-6189 


\section{Abstract}

Dental age estimation in living individuals is one of the most frequent requests undertaken by forensic odontologists. The aim of this study was to estimate the dental age by pulp/tooth volume ratio, as measured on cone beam computer tomography (CBCT) images, in a Spanish population. This study included 313 teeth from 107 adult individuals, 56 females and 51 males with a mean age of $44 \pm 14$ years. The statistical analysis of the results took account of clustering (multiple teeth in individuals). Linear regression models were constructed on the relationship between pulp/tooth volume ratio and chronological age for each tooth type. The highest coefficient of determination $\left(R^{2}\right)$ value was provided by the upper incisors (36.6\%) and, the difference between chronological and estimated age was less than 5 years in $31.3 \%$ of the sample and less than 10 years for $65.7 \%$. CBCT is an accurate imaging technique to measure dental volume with a relatively low radiation dose, and it can be used to assess dental age in living adult individuals. Volumetric changes in the pulp cavity with increasing age proved valuable to estimate dental age in this Spanish population.

Keywords: Forensic dentistry • Age estimation • Cone beam CT 


\section{Introduction}

Dental age estimation (DAE) is one of the most frequently asked questions in forensic odontology. There is a growing demand for DAE in living individuals (related to migratory movements, lack of documentation, memory loss, pensions, etc.) and children (related to adoption, underage marriage, legal responsibility, child pornography cases, etc.) [1]. The advantage of DAE is that teeth are less affected by extrinsic physical, chemical, or mechanical factors than are other parts of the skeleton. For this reason, DAE results have shown a low variability as a function of chronological age [2-5].

Forensic dentistry has become an important tool for age estimation [6]. In cadavers, dental age estimation has allowed the reconstruction of biological profiles through biochemical methods [7] in order to assist with the identification of the deceased. However, these methods require dental extraction (unethical in living individuals), are time-consuming, and require sophisticated laboratory equipment [8]. However, simple, inexpensive and accurate procedures are available for DAE in living subjects with developing teeth. These methods, based on the tooth formation and development, have been established as the most reliable and accurate means to estimate the age [9].

One well known DAE method is the measurement of pulp/tooth volume ratio [10], based on the progressive decrease in pulp volume caused by the continuous apposition of dentin throughout life [3]. Imaging techniques have been used for this method, but the accuracy of estimations on two-dimensional radiographs [11] is limited by magnification and distortion $[12,13]$. The increasing use of three-dimensional images in dental practice has led to research exploring the association between age and pulp/tooth volume ratio in samples from Belgium [3,14], Japan [15-19], India [12,20], Italy [21], China [22], Tunisia [23], and more recently, Malaysia [8,24], Brazil [25,26], Turkey [13,27] and Iran [28,29]. The results have indicated that age can be estimated with reasonable accuracy using three-dimensional images.

Cone beam computed tomography (СВCT) offers high-resolution images with relatively low doses of radiation [13] and offers a simple and conservative approach to the calculation of 
dental volume [21]. The aim of this study was to use CBCT images to calculate pulp/tooth volume ratios in teeth from a Spanish population with the purpose of improving the implementation of this imaging technique to estimate dental age in living individuals.

\section{Materials and Methods}

The study initially included 321 teeth obtained in the School of Dentistry at the University of Granada (Spain). Only healthy teeth were selected, excluding those that had been treated or presented cavities, restorations or excessive wear or attrition. Out of the initial sample of 321 healthy teeth, upper premolars were excluded due to their small number (a maximum total of 8 teeth). The final study sample therefore comprised 313 teeth (incisors, canines and lower premolars) from 107 patients: 56 females and 51 males with a mean age of $44 \pm 14$ yrs. (range, 14 - 70 yrs.) (Table 1). All CBCT images had been documented for valid clinical reasons by the same radiological technician, using a Cone Beam Computed Tomography Planmeca Pro Max (Planmeca Co., Helsinki, Finland). Exposures were taken at $90 \mathrm{Kv}$ and $12-14 \mathrm{~mA}$, with a scanning time of $12 \mathrm{sec}$. The study was conducted in accordance with the Declaration of Helsinki and was approved by the Granada University Ethics Committee for Research Involving Human Subjects.

Since previous studies found virtually no difference in radiographic adult age determination between teeth from the left and right side of the dental arch $[3,10,17,27]$, left and right teeth were pooled in the analyses.

The CBCT images were analyzed using Planmeca Romexis 2.3.1.R software (Helsinki, Finland). The crown volume (CV) was calculated by using the "Cube tool" to delineate an area from the cementum-enamel junction (CEJ) to the incisal edge of the tooth in three spatial axes (axial, sagittal, and coronal). Segmentation of the crown was automatically performed by setting grayscale thresholds for the enamel, dentin and pulp. The crown pulp volume (CPV) was calculated using the same procedure but delineating the area from the

CEJ to the roof of the pulp chamber in three spatial axes and separating the coronal pulp by 
setting a grayscale threshold. The program automatically calculated the volumes of the crown (CV) and pulp chamber (CPV) from the 3D images (Fig. 1). The pulp chamber/crown volume ratio was calculated for each tooth.

To determine the reliability of the method, a previous pilot study was conducted, with two observers measuring the CV and CPV in 33 teeth. Intraclass Correlation Coefficients (ICCS) were calculated. ICC was 0.83 for CV and 0.63 for CPV, considered "almost perfect" and "substantial" concordance, respectively [30].

\section{Statistical analysis}

IBM SPSS Statistics v.23.0 (IBM Corp., Armonk, NY, USA) was used for the descriptive analysis (percentages, means, and standard deviations) and for the linear regression (true age as dependent variable, and $\log _{10}(\%$ pulp) as independent variable) to obtain the estimated

(predicted) age for each type of tooth. Use was made of the adjusted predicted value, i.e., removing each patient from the data set, fitting the regression model with the remaining data and then using this model to make age prediction of the omitted patient, with this algorithm being repeated. Hence, the data of a given patient was not used to calculate his/her estimated age, thereby yielding unbiased age estimates. To estimate the age, upper central and lateral incisors were pooled together, as were lower central and lateral incisors, and lower first and second premolars in order to increase the sample size. SUDAAN 7.0 (Research Triangle Institute, Research Triangle Park, NC) was used for analytical purposes to account for clustering, i.e., multiple teeth $(n=313)$ in patients $(n=107)$. SUDAAN enables to obtain consistent estimates of $\mathrm{P}$ values, standard errors and $95 \%$-Cls for cluster-correlated data, after the application of the Taylor series method [31]. The statistical methods are also described in the corresponding table captions. 

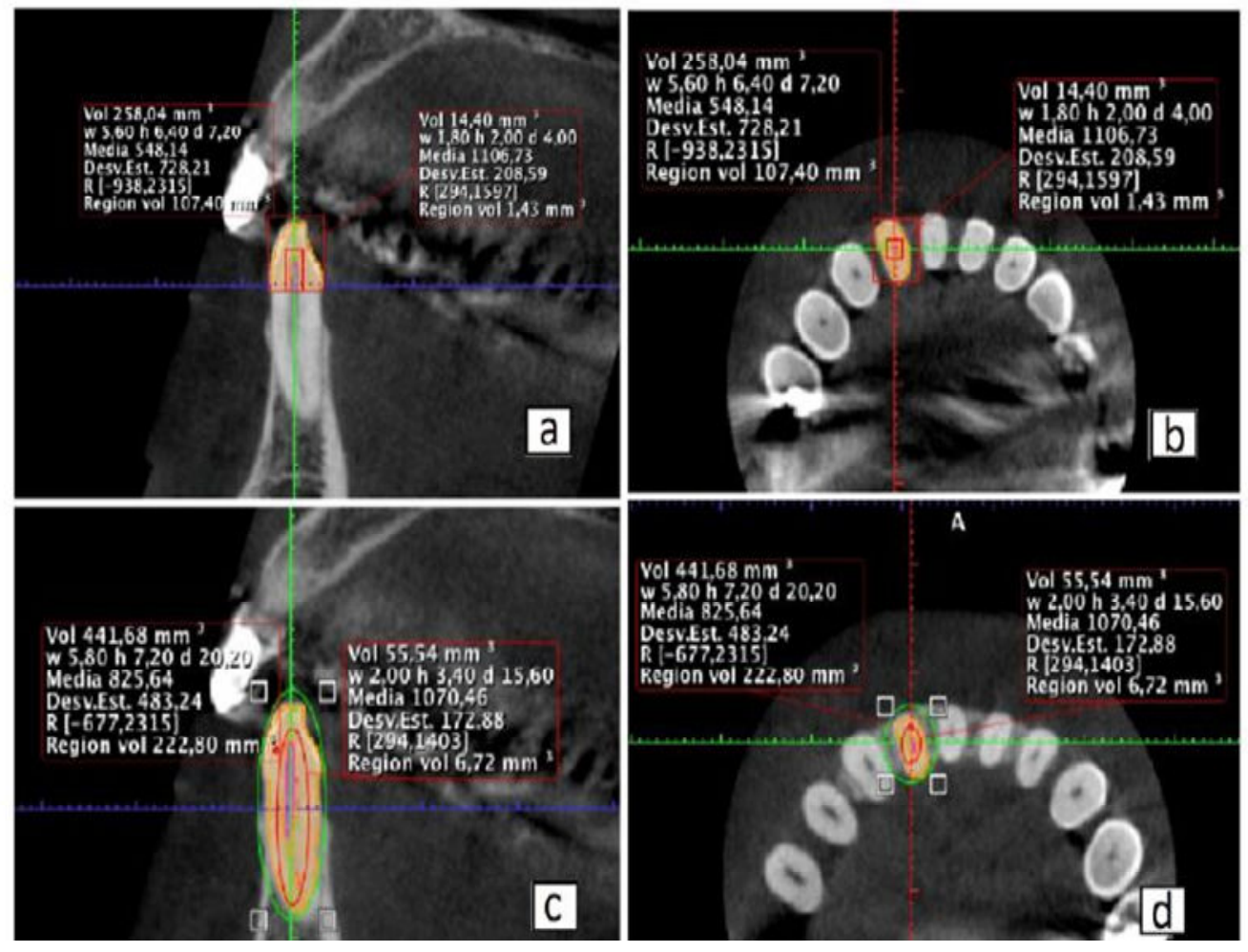

Fig. 1 Automatic calculation of the crown volume and the entire tooth with CBCT images analyzed using Planmeca Romexis 2.3.1.R software (a) volume of dental hard tissues and pulp volume of the dental crown (sagittal section) (b) volume of dental hard tissues and pulp volume of the dental crown (axial section) (c) volume of dental hard tissues and pulp volume of the whole tooth (sagittal section) (d) volume of dental hard tissues and pulp volume of the whole tooth (axial section). 


\section{Results}

Table 2 exhibits the distribution of tooth types and pulp/tooth volume ratios in this study. The tooth type of each hemiarch (left and right side) was combined, and the regression procedure to account for clustering (multiple teeth in subjects). The mean CPV was 469 \pm 162 $\mathrm{mm}^{3}$, and the mean pulp chamber/crown ratio was $8.8 \pm 2.7 \%$. By tooth type, the CV ranged from $277 \pm 50 \mathrm{~mm}^{3}$ for the lower central incisor to $659 \pm 127 \mathrm{~mm}^{3}$ for the upper central incisor. Tooth types significantly differed in CV and ratio: pulp chamber/crown volume. No significant differences were found between males and females (results not shown). Linear regression models between pulp/tooth volume ratio and chronological age for each type of teeth are shown in Table 3. The highest coefficient of determination $\left(R^{2}\right)$ value was for the upper incisors (36.6\%). All associations were statistically significant except for the upper and lower canines which had the lowest $R^{2}$ values.

Table 4 displays the differences between chronological age and estimated age for each tooth type in linear regression models. Canines were excluded due to previous results. For upper incisors, the difference between chronological and estimated age was $<5$ years in $31.3 \%$ of the teeth and $5-10$ years in $34.4 \%$; thus, the difference was $<10$ years in $65.7 \%$ of these teeth. For the lower incisors, the difference was $<5$ years in $30.1 \%$ of samples, and $<10$ years in $55.9 \%$. The mean difference between chronological and estimated age was 8.0 years for upper incisors, and 9.6 years for lower incisors. The largest mean difference was for the lower premolars (12.6 years)

\section{Discussion}

The progressive decrease of pulp volume over time has been used to estimate dental age in adult individuals [3, 8, 12-27], although the apposition of secondary dentine is not homogeneous on all walls of the pulp cavity [21]. Difficulties have been reported in detecting minute structural demarcations at the root apex (pulp tissue and calcified tooth structures) and undertaking this manually for this purpose would be time-consuming [8]. Rai et al. found a significant association between chronological age and pulp/tooth volume ratio using CBCT axial planes at the CEJ but not employing coronal planes or sagittal planes 
of CBCT; they attributed this finding to the clearer demarcation of pulp and tooth outline in the CEJ section compared with more apical sections [20]. In 2018, Asif and colleagues [24] used two approaches to volumetric analysis to examine the relationship between chronological age and pulp/tooth volume ratios: pulp cavity/tooth ratio and pulp chamber/crown ratio (up to CEJ). Although both methods obtained a strong correlation with chronological age, the coefficient of determination was higher with the pulp chamber/crown ratio method $\left(R^{2}=0.78\right)$, which required less time and achieved greater inter-examiner reliability (0.982), since no manual intervention is needed for 'multiple slice editing phase' of the software [24]. This paper used the pulp chamber/crown ratio in the same way in order to strengthen the power of the results and save time.

In 2015, Porto et al. [25] reported a weak correlation between the pulp cavity/tooth volume ratio in upper central incisors and age (coefficient of determination of 0.21 ), which they attributed to tertiary dentine deposition due to external stimuli. In our analysis, a post-study evaluation of sample size indicated that this was sufficient to estimate the absolute age difference, with a precision of less than 5 years and 95\%-confidence interval for each tooth type (Table 4). Indeed, $36.6 \%$ of the age variability was explained by the pulp chamber/crown volume ratio for upper incisors, and the differences between chronological and estimated age was $<5$ years for $31.3 \%$ of these teeth. Similar results have been published by other authors, indicating that the pulp tooth volume ratio of incisors offers a reliable DAE method $[3,8,13,16,26-28]$. However, results for canines did not prove to be a reliable approach to age estimation in this Spanish population, unlike findings in Malaysian [8], Tunisian [23], Iranian [28], Indian [12], and Pakistani [32] populations. Incisors showed a stronger correlation in the study by Star et al. [3], although they examined only a small number of canines and premolars. Gulsahi et al. [13] assessed similar numbers for all tooth types and found the strongest age correlation on upper central incisors, followed by upper lateral incisors, proposing that the weaker correlations found for canines may be attributed to the different qualities of their dentinal deposition in comparison with other tooth types. Nemsi et al. [23] also analyzed canines, but their results cannot be compared with our findings due to differences in the technique employed, given that they used an axial CBCT 
section of $\mathrm{CBCT}$ but excluded the enamel. Another study examined canine volumes alone and found a stronger relationship with chronological age in lower rather than upper canines [32]; and reported that this relationship was nonlinear, and that age estimation was highly influenced by sample size and methods employed.

No statistically significant differences in pulp chamber/crown volume ratio were found between the sexes in our study, as previously reported $[8,21]$. Although Star et al. observed a stronger correlation between pulp/tooth volume ratio and age in women compared to men, the difference was not statistically significant [3]. By contrast, statistically significant differences between the sexes have been found by other authors $[15,22,28,32]$. In agreement with other studies, there is a need to consider different tooth types with recognized differences in tissue volumes and sexual dimorphism. To our knowledge, this is the first study to use pulp/tooth volume ratio for DAE in a Spanish population. Besides the limited sample size, the different methodology compared to previous studies limit any comparisons with their results. As noted by Maret et al. [33] rapid developments in CBCT technology have markedly improved its usefulness for DAE over a short period of time. Multicenter studies are needed to validate equations for tooth types according to sex more efficiently. In line with previous studies above mentioned, CBCT measurements of upper incisors appear to offer the most accurate DAE with this method.

\section{Conclusions}

According to this study, the strongest correlation with DAE using CBCT in this Spanish sample, was found for the upper incisors, followed by the lower incisors. The difference between the chronological and estimated age was less than 5 yrs. for $31.3 \%$ of the sample. The upper and lower canines showed no statistically significant association with DAE. Neither were any significant differences found between the sexes. Future studies may focus on standardizing methodologies across several different populations and taking into account differences according to sex and tooth type. 


\section{Compliance with ethical standards}

High standard of ethics according to the WMA Declaration of Helsinki was applied in all investigations described in the manuscript. The research project was approved by the Granada University Ethics Committee for Research Involving Human Subjects.

\section{Funding information}

This study is partially supported by the Ministry of Science, Innovation and Universities of Spain (PRX19/00369).

\section{Conflict of interest}

The authors declare that they have no conflict of interest. 
Table 1 Descriptive statistics: Subjects $(\mathrm{n}=107)^{\mathrm{a}}$

\begin{tabular}{lc}
\hline Variable & $\mathrm{n}(\%)$ \\
\hline Sex & $51(47.7)$ \\
Male & $56(52.3)$ \\
Female & \\
\hline Age (years) & $8(7.5)$ \\
$14-20$ & $17(15.9)$ \\
$21-30$ & $13(12.1)$ \\
$31-40$ & $25(23.4)$ \\
$41-50$ & $34(31.8)$ \\
$51-60$ & $10(9.3)$ \\
$69-70$ & $44 \pm 14$ \\
Mean \pm sd & \\
\hline Number of teeth & $34(31.8)$ \\
1 & $23(21.5)$ \\
2 & $18(16.8)$ \\
3 & $10(9.3)$ \\
4 & $12(11.2)$ \\
5 & $10(9.3)$ \\
$\geq 6$ & $2.93 \pm 2.14$ \\
Mean \pm sd &
\end{tabular}

${ }^{a}$ These subjects accumulate 313 teeth for the analyses.

Table 2 Volume of crown (mm3) and pulp chamber/crown volume ratio $(\%)(\mathrm{n}=313$ teeth, 107 subjects)

Table 2 Volume of crown $\left(\mathrm{mm}^{3}\right)$ and pulp chamber/crown volume ratio $(\%)(\mathrm{n}=313$ teeth, 107 subjects $)$

\begin{tabular}{lccc}
\hline Teeth & $\mathrm{n}$ & $\begin{array}{c}\text { Crown } \\
\text { volume } \\
\left(\mathrm{mm}^{3}\right)\end{array}$ & $\begin{array}{c}\% \text { Pulp } \\
\text { mean } \pm \text { sd } \\
\text { mean } \pm \text { sd }\end{array}$ \\
\hline Total & 313 & $469 \pm 162$ & $8.8 \pm 2.7$ \\
11-21 (Upper central incisors) & 17 & $659 \pm 127$ & $6.1 \pm 1.9$ \\
$12-22$ (Upper lateral incisors) & 15 & $438 \pm 112$ & $7.7 \pm 2.6$ \\
13-23 (Upper canines) & 34 & $636 \pm 126$ & $8.5 \pm 2.4$ \\
$31-41$ (Lower central incisors) & 42 & $277 \pm 50$ & $8.4 \pm 2.0$ \\
$32-42$ (Lower lateral incisors) & 51 & $328 \pm 67$ & $8.3 \pm 2.2$ \\
$33-43$ (Lower canines) & 97 & $539 \pm 138$ & $9.5 \pm 2.9$ \\
$34-44$ (Lower first premolars) & 42 & $464 \pm 94$ & $9.3 \pm 2.6$ \\
$35-45$ (Lower second premolars) & 15 & $488 \pm 106$ & $9.6 \pm 3.9$ \\
Global p-value & & $<0.001$ & $<0.001$ \\
\hline a Employing SUDAAN regression procedure to account for clustering (multiple teeth within the subjects).
\end{tabular}


Table 3 Linear regression models, with pulp/crown volume ratio as independent variable, and age as dependent variable ( $\mathrm{n}=\mathbf{3 1 3}$ teeth, 107 subjects), according to tooth type a

\begin{tabular}{|c|c|c|c|c|c|}
\hline \multirow[t]{2}{*}{ Type of tooth } & \multirow[b]{2}{*}{$\mathrm{n}$} & \multirow[b]{2}{*}{$\mathrm{R}^{2}$} & \multicolumn{3}{|c|}{ Equation: Constant $+\beta \times\left[\log _{10}\left(X^{b}\right)\right]$} \\
\hline & & & Constant & $\beta \pm \mathrm{se}^{\mathrm{c}}$ & p-value ${ }^{c}$ \\
\hline Upper incisors & 32 & 0.366 & 69.9 & $-42.8 \pm 10.3$ & $<0.001$ \\
\hline Upper canines & 34 & 0.028 & 57.6 & $-20.8 \pm 24.1$ & 0.390 \\
\hline Lower incisors & 93 & 0.167 & 83.6 & $-45.0 \pm 11.6$ & $<0.001$ \\
\hline Lower canines & 97 & 0.010 & 53.8 & $-9.9 \pm 11.4$ & 0.389 \\
\hline Lower premolars & 57 & 0.152 & 79.6 & $-43.3 \pm 12.0$ & $<0.001$ \\
\hline
\end{tabular}

a The interaction type of tooth $\times \log _{10} \%$ pulp was significant $(\mathrm{p}<0.001)$.

Furthermore, sex did not test significantly $\left(\mathrm{p}=0.564\right.$ in a model with $\log _{10} \%$ pulp,

tooth type and sex as independent variables).

${ }^{\mathrm{b}} \mathrm{X}=\%$ pulp.

${ }^{c}$ Standard errors (se) and p-values calculated with SUDAAN regress procedure,

to account for clustering (multiple teeth within the patient).

Table 4 Age differences (absolute values) between chronological age and estimated age with linear regression modelling ${ }^{\mathrm{a}}$ excluding canines ( $\mathrm{n}=182$ teeth, 79 subjects) ${ }^{\mathrm{b}}$.

\begin{tabular}{|c|c|c|c|c|c|c|c|c|c|}
\hline \multirow{3}{*}{ Tooth (only crowns) } & \multirow[b]{3}{*}{$\mathrm{n}$} & \multirow{3}{*}{$\begin{array}{c}\text { Age } \\
\text { mean } \pm \text { sd }\end{array}$} & \multicolumn{7}{|c|}{$\begin{array}{l}\text { Age differences (yrs) (absolute values) } \\
\text { between chronological and estimated age }\end{array}$} \\
\hline & & & \multicolumn{5}{|c|}{$\%$ distribution (yrs) } & \multicolumn{2}{|c|}{ Mean } \\
\hline & & & $0-5$ & $>5-10$ & $>10-15$ & $>15-20$ & $>20-33$ & mean \pm sd & $95 \%-\mathrm{CI}^{\mathrm{c}}$ \\
\hline [A] Upper incisors & 32 & $35.4 \pm 11.7$ & 31.3 & 34.4 & 21.9 & 9.4 & 3.1 & $8.0 \pm 5.7$ & $5.6-10.4$ \\
\hline [B] Lower incisors & 93 & $42.9 \pm 12.6$ & 30.1 & 25.8 & 20.4 & 17.2 & 6.5 & $9.6 \pm 6.6$ & $7.7-11.5$ \\
\hline [C] Lower premolars & 57 & $38.5 \pm 15.2$ & 19.3 & 14.0 & 29.8 & 22.8 & 14.0 & $12.6 \pm 6.8$ & $10.7-14.5$ \\
\hline Global p-value $\mathrm{e}^{\mathrm{a}}$ & & & & & & & & $\mathrm{p}=0.005$ & \\
\hline Paired comparisons ${ }^{\mathrm{d}}$ & & & & & & & & $\mathrm{AB} \neq \mathrm{C}$ & \\
\hline
\end{tabular}

a: Regression with SPSS, with predictive values estimated as adjusted values (see Methods).

b: After excluding upper $(n=42)$ and lower canines $(n=97)$, since their regression models were not statistically significant (see Table 3).

c: Confidence Intervals adjusted with SUDAAN Descript procedure, to adjust for multiple teeth within the patient.

d: With SUDAAN’s Descript procedure, where " $\neq$ " means $p<0.05$. 


\section{References}

1. Black S, Payne-James J, Aggrawal A (2010). Age estimation in the living: The practitioners guide. Wiley-Blackwell, Chichester.

2. Cameriere R, Cunha E, Wasterlain SN, De Luca S, Sassaroli E, Pagliara F, Nuzzolese E, Cingolani M, Ferrante L (2013) Age estimation by pulp/tooth ratio in lateral and central incisors by peri-apical X-ray. J Forensic Leg Med 20(5):530-536. doi: 10.1016/j.jflm.2013.02.012.

3. Star H, Thevissen P, Jacobs R, Fieuws S, Solheim T, Willems G (2011) Human Dental Age Estimation by Calculation of Pulp-Tooth Volume Ratios Yielded on Clinically Acquired Cone Beam Computed Tomography Images of Monoradicular Teeth. J Forensic Sci 56(1):S77-S82. doi: 10.1111/j.1556-4029.2010.01633.x.

4. Ge ZP, Ma RH, Li G, Zhang JZ, Ma XC (2015) Age estimation based on pulp chamber volume of first molars from cone-beam computed tomography images. Forensic Sci Int 253:133.e1-7. doi: 10.1016/j.forsciint.2015.05.004.

5. Reesu GV, Augustine J, Urs AB (2015) Forensic considerations when dealing with incinerated human dental remains. J Forensic Leg Med 29:13-17. doi: 10.1016/j.jflm.2014.10.006.

6. Senn DR, Stimson PG (2010). Forensic Dentistry, 2nd edn. Taylor \& Francis, Boca Raton.

7. Adserias-Garriga J, Thomas C, Ubelaker DH, Zapico SC (2018) When forensic odontology met biochemistry: Multidisciplinary approach in forensic human identification. Arch Oral Biol 87:7-14. doi: 10.1016/j.archoralbio.2017.12.001.

8. Asif MK, Nambiar P, Mani SA, Ibrahim NB, Khan IM, Lokman NB (2019) Dental age estimation in Malaysian adults based on volumetric analysis of pulp/tooth ratio using CBCT data. Leg Med (Tokyo) 36:50-58. doi: 10.1016/j.legalmed.2018.10.005. 
9. Sehrawat JS, Singh M (2017) Willems method of dental age estimation in children: A systematic review and meta-analysis. J Forensic Leg Med 52:122-129. doi: 10.1016/j.jflm.2017.08.017.

10. Marroquin TY, Karkhanis S, Kvaal SI, Vasudavan S, Kruger E, Tennant M (2017) Age estimation in adults by dental imaging assessment systematic review. Forensic Sci Int 275:203-211. doi: 10.1016/j.forsciint.2017.03.007.

11. Cameriere R, De Luca S, Aleman I, Ferrante L, Cingolani M (2012) Age estimation by pulp/tooth ratio in lower premolars by orthopantomography. Forensic Sci Int 214(1-3):105-112.

12. Jagannathan $N$, Neelakantan $P$, Thiruvengadam $C$, Ramani $P$, Premkumar $P$, Natesan A, Herald JS, Luder HU (2011) Age estimation in an Indian population using pulp/tooth volume ratio of mandibular canines obtained from cone beam computed tomography. J Forensic Odontostomatol 29(1):1-6.

13. Gulsahi A, Kulah CK, Bakirarar B, Gulen O, Kamburoglu K (2018) Age estimation based on pulp/tooth volume ratio measured on cone-beam CT images. Dentomaxillofac Radiol 47(1):20170239. doi: 10.1259/dmfr.20170239.

14. Yang F, Jacobs R, Willems G (2006) Dental age estimation through volume matching of teeth imaged by cone-beam CT. Forensic Sci Int 159(1):S78-83. doi: 10.1016/j.forsciint.2006.02.031.

15. Someda H, Saka H, Matsunaga S, Ide Y, Nakahara K, Hirata S, Hashimoto M (2009) Age estimation based on three-dimensional measurement of mandibular central incisors in Japanese. Forensic Sci Int 185(1-3):110-114. doi: 10.1016/j.forsciint.2009.01.001.

16. Agematsu $H$, Someda $H$, Hashimoto $M$, Matsunaga $S$, Abe S, Kim HJ, Koyama T, Naito H, Ishida R, Ide $Y$ (2010) Three-dimensional observation of decrease in pulp cavity volume using micro-CT: age-related change. Bull Tokyo Dent Coll 51(1):1-6. doi: 10.2209/tdcpublication.51.1. 
17. Aboshi H, Takahashi T, Komuro T (2010) Age estimation using microfocus X-ray computed tomography of lower premolars. Forensic Sci Int 200(1-3):35-40. doi: 10.1016/j.forsciint.2010.03.024.

18. Sakuma A, Saitoh H, Suzuki Y, Makino Y, Inokuchi G, Hayakawa M, Yajima D, Iwase H (2013) Age estimation based on pulp cavity to tooth volume ratio using postmortem computed tomography images. J Forensic Sci 58(6):1531-1535. doi: 10.1111/15564029.12175 .

19. Sue M, Oda T, Sasaki Y, Ogura I (2018) Age-related changes in the pulp chamber of maxillary and mandibular molars on cone-beam computed tomography images. Oral Radiol 34(3):219-223. doi: 10.1007/s11282-017-0300-1.

20. Rai A, Acharya AB, Naikmasur VG (2016) Age estimation by pulp-to-tooth area ratio using cone-beam computed tomography: A preliminary analysis. J Forensic Dent Sci 8(3):150-154. doi: 10.4103/0975-1475.195118.

21. Pinchi V, Pradella F, Buti J, Baldinotti C, Focardi M, Norelli GA (2015) A new age estimation procedure based on the 3D CBCT study of the pulp cavity and hard tissues of the teeth for forensic purposes: A pilot study. J Forensic Leg Med 36:150-157. doi: 10.1016/j.jflm.2015.09.015.

22. Ge ZP, Yang P, Li G, Zhang JZ, Ma XC (2016) Age estimation based on pulp cavity/chamber volume of 13 types of tooth from cone beam computed tomography images. Int J Legal Med 130(4):1159-1167. doi: 10.1007/s00414-016-1384-6.

23. Nemsi H, Haj Salem N, Bouanene I, Ben Jomaa S, Belhadj M, Mosrati MA, Aissaoui A, Ben Amor F, Chadly A (2017) Age assessment in canine and premolar by cervical axial sections of cone-beam computed tomography. Leg Med (Tokyo) 28:31-36. doi: 10.1016/j.legalmed.2017.07.004.

24. Asif MK, Nambiar P, Mani SA, Ibrahim NB, Khan IM, Sukumaran P (2018) Dental age estimation employing CBCT scans enhanced with Mimics software: Comparison of two different approaches using pulp/tooth volumetric analysis. J Forensic Leg Med 54:53-61. doi: 10.1016/j.jflm.2017.12.010. 
25. Porto LV, Celestino da Silva Neto J, Anjos Pontual AD, Catunda RQ (2015) Evaluation of volumetric changes of teeth in a Brazilian population by using cone beam computed tomography. J Forensic Leg Med 36:4-9. doi: 10.1016/j.jflm.2015.07.007.

26. Andrade VM, Fontenele RC, de Souza AC, Almeida CA, Vieira AC, Groppo FC, Freitas DQ, Junior ED (2019) Age and sex estimation based on pulp cavity volume using cone beam computed tomography: development and validation of formulas in a Brazilian sample. Dentomaxillofac Radiol. 48(7):20190053. doi: 10.1259/dmfr.20190053.

27. Uğur Aydın Z, Bayrak S (2019) Relationship Between Pulp Tooth Area Ratio and Chronological Age Using Cone-beam Computed Tomography Images. J Forensic Sci 64(4):1096-1099. doi: 10.1111/1556-4029.13986.

28. Biuki N, Razi T, Faramarzi M (2017) Relationship between pulp-tooth volume ratios and chronological age in different anterior teeth on CBCT. J Clin Exp Dent 9(5):e688e693. doi: 10.4317/jced.53654.

29. Haghanifar S, Ghobadi F, Vahdani N, Bijani A (2019) Age estimation by pulp/tooth area ratio in anterior teeth using cone-beam computed tomography: comparison of four teeth. J Appl Oral Sci 27:e20180722. doi: 10.1590/1678-7757-2018-0722.

30. Landis JR, Koch GG (1977) The measurement of observer agreement for categorical data. Biometrics 33(1):159-174.

31. Shah BV, BarnWell BG, Bieler GS (1996). SUDAAN software for the statistical analysis of correlated data. User's manual. Release 7.0. Research Triangle Institute, Research Triangle Park, NC.

32. Kazmi S, Mânica S, Revie G, Shepherd S, Hector M (2019) Age estimation using canine pulp volumes in adults: a CBCT image analysis. Int J Legal Med 133(6):19671976. doi: 10.1007/s00414-019-02147-5.

33. Maret D, Peters OA, Dedouit F, Telmon N, Sixou M (2011) Cone-Beam Computed Tomography: a useful tool for dental age estimation? Med Hypotheses 76(5):700-2. doi: 10.1016/j.mehy.2011.01.039. 